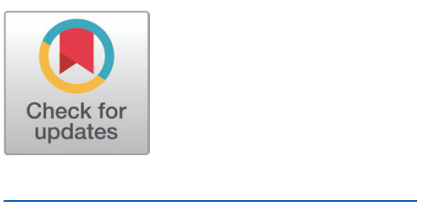

Received: Aug 18, 2021

Revised: Sep 30, 2021

Accepted: Nov 12, 2021

*Corresponding author Jongkyoo Kim

Department of Animal Science \& Food Science and Human Nutrition, Michigan State University, East Lansing, MI 48824, USA.

Tel: +1-517-355-8415

E-mail: Kimjon48@msu.edu

Copyright ( $\subset 2021$ Korean Society of Animal Sciences and Technology. This is an Open Access article distributed under the terms of the Creative Commons Attribution Non-Commercial License (http:// creativecommons.org/licenses/by$\mathrm{nc} / 4.0 /$ ) which permits unrestricted non-commercial use, distribution, and reproduction in any medium, provided the original work is properly cited.

ORCID

Ki Yong Chung

https://orcid.org/0000-0003-0957-875X Jongkyoo Kim

https://orcid.org/0000-0002-4827-5762

Bradley J. Johnson

https://orcid.org/0000-0001-9162-9661

Competing interests

No potential conflict of interest relevant to this article was reported.

Funding sources

This study supported in part by

\section{All-trans retinoic acid alters the expression of adipogenic genes during the differentiation of bovine intramuscular and subcutaneous adipocytes}

\author{
Ki Yong Chung ${ }^{1}$, Jongkyoo Kim ${ }^{2 *}$ and Bradley J. Johnson ${ }^{3}$ \\ ${ }^{1}$ Department of Beef Science, Korea National College of Agriculture and Fisheries, Jeonju 54874, Korea \\ ${ }^{2}$ Department of Animal Science \& Food Science and Human Nutrition, Michigan State University, East \\ Lansing, MI 48824, USA \\ ${ }^{3}$ Department of Animal and Food Science, Texas Tech University, Lubbock, TX 79409, USA
}

\begin{abstract}
The present study was designed to determine the influence of all-trans retinoic acid (ATRA) on adipogenesis-related gene regulation in bovine intramuscular (IM) and subcutaneous (SC) adipose cells during differentiation. Bovine IM and SC adipocytes were isolated from three 19-mo-old, crossbred steers. Adipogenic differentiation was induced upon cultured IM and SC preadipocytes with various doses $(0,0.001,0.01,0.1,1 \mu \mathrm{M})$ of ATRA. After $96 \mathrm{~h}$ of incubation, cells were harvested and used to measure the gene expression of CCAAT/Enhancer binding protein $\beta(C / E B P \beta)$, peroxisome proliferator-activated receptor (PPAR) $\gamma$, glucose transporter 4 (GLUT4), stearoyl CoA desaturase (SCD), and Smad transcription factor 3 (Smad3) relative to the quantity of ribosomal protein subunit 9 (RPS 9). Retinoic acid receptor (RAR) antagonist also tested to identify the effect of ATRA on PPARY -RAR related gene expression in IM cells. The addition of ATRA to bovine IM decreased $(p<0.05)$ expression of PPARy. The expression of PPARY was also tended to be downregulated $(p<0.1)$ in high levels $(10 \mu \mathrm{M})$ of ATRA treatment in SC cells. The treatment of RAR antagonist increased the expression of PPARY in IM cells. Expression of C/EBP $\beta$ decreased $(p<0.05)$ in $\mathrm{SC}$, but no change was observed in IM ( $p>0.05)$. Increasing levels of ATRA may block adipogenic differentiation via transcriptional regulation of PPARY. The efficacy of ATRA treatment in adipose cells may vary depending on the location.
\end{abstract}

Keywords: Bovine intramuscular adipose tissue, Marbling, Retinoic acid receptor antagonist

\section{INTRODUCTION}

In the current beef industry, intramuscular (IM) fat contents are critical factors in determining the beef quality and economic value. Increasing days on feed with a grain-based diet is a common and widely used strategy to maximize the marbling of beef without modifying the genetics of animals. This 
funding from the Gordon W. Davis Regents Chair Endowment at Texas Tech University and partially supported from Cooperative Research Program for Agriculture Science \& Technology Development (Project No. PJ0150252021) Rural Development Administration, Korea.

Acknowledgements Not applicable.

Availability of data and materia Upon reasonable request, the datasets of this study can be available from the corresponding author.

Authors' contributions

Conceptualization: Chung KY, Kim J . Data curation: Chung KY, Kim J. Formal analysis: Chung KY, Kim J.

Methodology: Chung KY, Kim J, Johnson BJ. Software: Chung KY, Kim J.

Validation: Johnson BJ.

Investigation: Chung KY, Kim J.

Writing - original draft: Chung KY, Kim J.

Writing - review \& editing: Kim J, Johnson BJ.

Ethics approval and consent to participate This article does not require IRB/IACUC approval because there are no human and animal participants. feeding strategy can decrease feed efficiency and increase backfat thickness simultaneously. Since energy costs increase as the proportion of gain as internal or subcutaneous (SC) fat [1], an increased amount of that adipose tissue may be less desirable. There have been efforts to increase IM fat intensively without altering other, economically valueless adipose tissues. With the long-period selection, Wagyu and Hanwoo cattle showed high-marbling traits with less backfat thickness while feeding grain-based diets with around 30-month of the feeding period. At the same time, researchers also have been searching for nutritional methods to increase IM fat, such as a vitamin A-deficient diet. The long-term depletion of vitamin $\mathrm{A}$ has commonly been used in a few countries to increase IM adipose tissue accumulation [2]. Multiple vitamin A isoforms, including 9- cis retinoic acid and all-trans-retinoic acid reported as an inhibitor of peroxisome proliferator-activated receptor $\gamma(\mathrm{PPAR} \gamma)$ and retinoid $\mathrm{X}$ receptor (RXR). Among various vitamin A isoforms, alltrans retinoic acid (ATRA) is known to be the most active isoform in mammals. It has numerous physiological effects such as vision, embryonic development, reproduction, hematopoiesis, and differentiation of epithelial and mesenchymal cells. It also reported that dietary vitamin A negatively affects the development of adipose tissues in mammalian animals [3-5]. Therefore, ATRA has been chosen as a vitamin A source in the current study. In countries where marbling is the most important factor for consumer's beef choice, vitamin A or provitamin A-deficient diets have been used for beef cattle to maximize IM fat accumulation [2]. Inhibitory effects of vitamin A isoforms have been tested with various cell and animal types such as swine [6], cattle [7], and rodents $[8,9]$. Nevertheless, much is unknown about the biological metamorphosis of adipocytes, which have many differences across species and peripheral adipose depots. Therefore, this study was conducted to determine the influence of ATRA on genes associated with adipogenic differentiation of bovine $\mathrm{SC}$ and IM adipocytes.

\section{MATERIALS AND METHODS}

\section{Primary preadipocytes isolation}

IM preadipocytes were isolated from three 16- month- old, crossbred steers (predominantly Angus, $474.5 \pm 50.2 \mathrm{~kg}$ ). Cattle were harvested in the Meat Science Laboratory (abattoir) at Texas Tech (Lubbock, TX, USA) under United States Department of Agriculture (USDA) inspection and exsanguinated following captive bolt stunning. Bovine IM adipose tissue was collected from between the 10th and 13th rib sections of the longissimus dorsi (LD) muscle (Fig. 1). SC adipose tissue was collected from the 10th and 13th rib areas immediately after the skin was removed. Isolated LD muscle SC adipose tissue and a chunk were promptly transported to the Texas Tech University Meat Science and Muscle Biology Laboratory (Lubbock, TX) in cold sterilized phosphate-buffered saline (PBS; Gibco, Waltham, MA, USA) with $3 \times$ Antibiotic-Antimycotic (Gibco). The IM fat tissue was dissected from LD, excluding connective tissue, blood vessels, and skin was removed. Both IM and SC Adipose tissues were minced finely and incubated in the warm digestion medium, containing Earl's Balanced Salt Solution (EBSS, Sigma-Aldrich, St. Louis, MO, USA), $0.1 \%$ of type IV collagenase (Thermo Fisher Science, Waltham, MA, USA), and $1 \times$ Antibiotic-Antimycotic (Gibco) for 40 minutes at $38^{\circ} \mathrm{C}$. The collagenase-digested adipose tissue was filtered through a $100 \mu \mathrm{m}$ nylon membrane, and the suspension was then centrifuged for 5 min at 2,000×G. After discarding the supernatant and lipid layer, the pellet was washed 3 times in Dulbecco's Modified Eagle Medium (DMEM). The pellet was re-suspended and maintained in growth media composed of DMEM (Gibco), 10\% fetal bovine serum (FBS, Gibco), and 1× Antibiotic-Antimycotic (Gibco) at $37^{\circ} \mathrm{C}$ under a humidified atmosphere of $5 \% \mathrm{CO}_{2}$. Upon reaching approximately $90 \%$ confluency, the growth medium was replaced by differentiation 


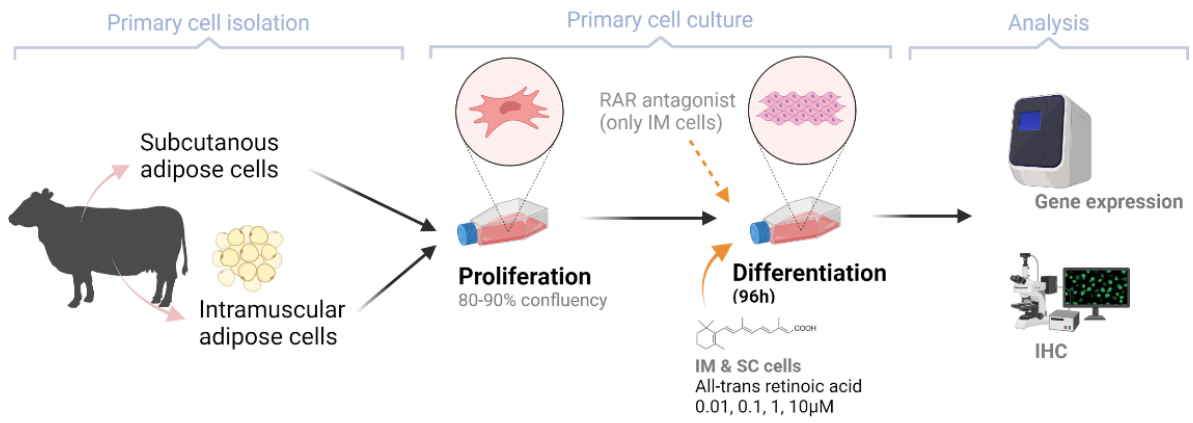

Fig. 1. Schematic illustration of cell culture procedure. Primary cell isolation: the intramuscular (IM) (dissected from LD) and subcutaneous fat tissue were isolated from three 16- month- old, crossbred steers, and incubated digestion medium; containing Earl's Balanced Salt Solution, $0.1 \%$ of type IV collagenase, and $1 \times$ Antibiotic-Antimycotic (Gibco, Waltham, MA, USA) for 40 minutes at $38^{\circ} \mathrm{C}$. Primary cell culture: bovine IM and subcutaneous (SC) preadipocytes were isolated from a beef steer. Preadipocytes were incubated in $10 \%$ FBS/DMEM with $1 \times$ Antibiotic-Antimycotic upon reaching $80 \%-90 \%$ confluency. Following that, adipogenic differentiation was induced by the addition of differentiation media containing $5 \%$ FBS, insulin $(10 \mu \mathrm{g} / \mathrm{mL})$, hydrocortisone $(10 \mu \mathrm{g} / \mathrm{mL})$, ciglitizone $(5 \mu \mathrm{M})$, and $1 \times$ Antibiotic-Antimycotic. Different doses $(0,0.001,0.01,0.1$, and $1 \mu \mathrm{M}$ ) of all-trans retinoic acid (ATRA) and retinoic acid receptor (RAR) antagonist (ANT; $1 \mu \mathrm{M})$ were added into the differentiation media. Analysis: After $96 \mathrm{~h}$ of incubation with differentiation media, cells were harvested and used for mRNA gene expression analysis, oil red $\mathrm{O}$ staining (ORO), and immunohistochemistry.

media composed of DMEM (Gibco), 5\% FBS (Gibco), $10 \mu \mathrm{g} / \mathrm{mL}$ insulin (Sigma-Aldrich), 10 $\mu \mathrm{g} / \mathrm{mL}$ hydrocortisone (Sigma-Aldrich), $5 \mu \mathrm{M}$ ciglitizone (Sigma-Aldrich), and 1× AntibioticAntimycotic (Gibco) with doses of 0 (Con), 0.01, 0.1, 0.1, $1 \mu \mathrm{M}$, and $10 \mu \mathrm{M}$ of ATRA (SigmaAldrich). In addition to this, $1 \mu \mathrm{M}$ of retinoic acid receptor (RAR) antagonist (ANT; AGN 193109 sodium salt, Santa Cruz Biotechnology, Dallas, TX, USA) was used in a dose-dependent manner, 0 (Con), $0.01,0.1,1 \mu \mathrm{M}$, and $10 \mu \mathrm{M}$ for $24 \mathrm{~h}$ and $96 \mathrm{~h}$ of incubation.

\section{Morphological staining}

After $96 \mathrm{~h}$ of differentiation, the plates were removed from the incubator and rinsed three times with PBS. The fixation of IM cells was conducted using 10\% formalin (Sigma-Aldrich) for $10 \mathrm{~min}$. Lipid droplets were stained using a $0.5 \%$ Oil Red O solution (ORO, Sigma-Aldrich) in propylene glycol (Sigma). After $1 \mathrm{~h}$ of incubation with ORO solution in a dark room, plates were rinsed with de-ionized (DI) water. Plates were then stained using Mayer's hematoxylin (Sigma-Aldrich) for $20 \mathrm{~min}$ to visualize nuclei. All cells were imaged with a Nikon Eclipse Ti-U microscope (Nikon Instruments, Tokyo, Japan). Images were processed using NIS-Elements software (Nikon Instruments).

\section{Real time-polymerase chain reaction (PCR) sample preparation and RNA isolation}

Cultured IM and SC preadipocytes were trypsinized (Sigma-Aldrich) and centrifuged for 5 min at 300×g. Total RNA isolation and purification steps were performed using the RNeasy ${ }^{\circledR}$ Mini kit (Qiagen, Germantown, MD, USA) according to manufacturer recommendation. The concentration and purity of RNA were measured with a spectrophotometer at an absorbance of $260 \mathrm{~nm}$ and $280 \mathrm{~nm}$ using a NanoDrop 1000 (NanoDrop Technologies, Wilmington, DE, USA). An acceptable range of 1.76 to 2.05 was used for the 260/280 ratio. Genomic DNA removal and cDNA synthesis were conducted using QuantiTect reverse transcription kit (Qiagen) according to manufacturer recommendations. Real-time quantitative PCR (7900-HT Real-Time PCR System, Applied Biosystems, Foster City, CA, USA) was used to measure the quantity of CCAAT/Enhancer binding protein (C/EBP) $\beta, P P A R \gamma$, glucose transporter 4 (GLUT4), stearoyl CoA desaturase (SCD), 
and Smad transcription factor 3 (SMAD3) relative to the quantity of ribosomal protein subunit 9 (RPS 9) mRNA in total RNA (Table 1). Since the expression of RPS9 did not differ across samples nor treatments, $R P S 9$ was used as the endogenous control in order to normalize the expression of genes. Measurement of the relative quantity of the cDNA of interest was carried out using TAMRA PCR Master Mix (Applied Biosystems) using the appropriate forward and reverse primers and cDNA mixture. Assays were performed in triplicate determinations using the thermal cycling parameters recommended by the manufacturer $\left(40\right.$ cycles of $15 \mathrm{~s}$ at $95^{\circ} \mathrm{C}$ and $1 \mathrm{~min}$ at $\left.60^{\circ} \mathrm{C}\right)$. Titration of mRNA primers against increasing amounts of $\mathrm{cDNA}$ yielded linear responses with slopes between -2.8 and -3.0. The RQ manager (Applied Biosystems) analyzed real-time quantitative (RQ) values based on $\Delta \Delta \mathrm{CT}$.

\section{Immunohistochemistry}

Cells were grown on 3-well microscopy glass slides (Ibidi USA, Fitchburg, WI, USA) for $96 \mathrm{~h}$ after inducing differentiation. Slides were fixed with cold $4 \%$ paraformaldehyde (Thermo Fisher Scientific) for $10 \mathrm{~min}$ at room temperature. In order to prevent nonspecific background staining, fixed cells were incubated in the blocking solution containing $2 \%$ bovine serum albumin (Thermo Fisher Scientific), 5\% of horse serum (Thermo Fisher Scientific), and 0.2\% Triton X-100 in PBS for $30 \mathrm{~min}$ at room temperature. Fixed cells were then incubated with primary antibody anti-

Table 1. Primer and probe sequences for the gene expression analysis

\begin{tabular}{|c|c|}
\hline Genes & Sequence ( $5^{\prime}$ to $\left.3^{\prime}\right)$ \\
\hline \multicolumn{2}{|l|}{ CEBP $\beta$} \\
\hline Forward & CCAGAAGAAGGTGGAGCAACTG \\
\hline Reverse & TCGGGCAGCGTCTTGAAC \\
\hline TaqMan probe & 6FAM-CGCGAGGTCAGCACCCTGC-TAMRA \\
\hline \multicolumn{2}{|l|}{ GLUT4 } \\
\hline Forward & CCTCGGCAGCGAGTCACT \\
\hline Reverse & AAACTGCAGGGAGCCAAGAA \\
\hline TaqMan probe & 6FAM- CCTTGGTCCTTGGCGTATTCTCCGC-TAMRA \\
\hline \multicolumn{2}{|l|}{ PPARY } \\
\hline Forward & ATCTGCTGCAAGCCTTGGA \\
\hline Reverse & TGGAGCAGCTTGGCAAAGA \\
\hline TaqMan probe & 6FAM-CTGAACCACCCCGAGTCCTCCCAG-TAMRA \\
\hline \multicolumn{2}{|l|}{ RPS9 } \\
\hline Forward & GAGCTGGGTTTGTCGCAAAA \\
\hline Reverse & GGTCGAGGCGGGACTTCT \\
\hline TaqMan probe & 6FAM-ATGTGACCCCGCGGAGACCCTTC-TAMRA \\
\hline \multicolumn{2}{|l|}{$S C D$} \\
\hline Forward & TGCCCACCACAAGTTTTCAG \\
\hline Reverse & GCCAACCCACGTGAGAGAAG \\
\hline TaqMan probe & 6FAM-CCGACCCCCACAATTCCCG-TAMRA \\
\hline \multicolumn{2}{|l|}{ SMAD3 } \\
\hline Forward & CGTCCATCCTGCСTTTCACT \\
\hline Reverse & TTCTGCTCGCCCTTTTTCC \\
\hline TaqMan probe & 6FAM-CCCGATCGTGAAGCGCCTGCT-TAMRA \\
\hline
\end{tabular}

C/EBP $\beta$, CCAAT/enhancer-binding protein $\beta$; GLUT4, glucose transporter 4; PPAR $\gamma$, peroxisome proliferated activate receptor $\gamma$; $R P S 9$, ribosomal protein subunit 9 ; $S C D$, stearoyl CoA desaturase; SMAD3, SMAD family member 3. 
$\operatorname{PPAR} \gamma$ (rabbit polyclonal, dilution 1:100; Abcam, Cambridge, UK) at $4{ }^{\circ} \mathrm{C}$ overnight.

The colorization of F-actin was conducted using Bodipy (558/568) phalloidin (Thermo Fisher Scientific) according to the manufacture's guidance. Nuclei were stained with 4',6-diamidino-2phenylindole (DAPI, Thermo Fisher Scientific) for $5 \mathrm{~min}$. Slides were imaged at a magnification of 20X using an inverted fluorescence microscope (Nikon Eclipse, Ti-E; Nikon Instruments) equipped with a UV light source (C-HGFIE, Nikon Intensilight, Tokyo, Japan). The NIS Elements ${ }^{\circledR}$ imaging software analyzed all images.

\section{Statistical analysis}

Gene expression data were analyzed as a completely randomized design using the MIXED procedure of SAS 9.4 (SAS Inst., Cary, NC, USA) using orthogonal contrasts for the dose-effect analysis. All results were reported as least-squares means. An $\alpha$ level of 0.05 was used to determine significance, with tendencies discussed at $P$-values between 0.05 and 0.10 .

\section{RESULTS AND DISCUSSION}

IM adipose tissue, also known as marbling fat in the meat industry, displays distinctive characteristics from other adipose tissues, primarily through their unique location and cellular level metabolism [4]. IM adipose cells are located within the perimysium alongside myofibers [10]. Due to its unique location, it is considered that this adipose tissue may closely communicate with neighboring muscle cells.

\section{Key transcription factors during adipogenic differentiation}

There are two distinctive phases during adipogenesis, which are determination (proliferation) and differentiation. During the determination period, adipocyte precursor cells and preadipocytes stay in the cell cycle and increase numbers through mitosis. While the differentiation process of preadipocytes into mature adipocytes is well-studied, a large portion of adipogenic determination is still unknown. Various transcriptional regulation events occur during adipogenic differentiation. The majority of them are associated mainly with the PPAR $\gamma$ or $C / E B P$ family, which are often referred to as key transcription factors $[4,11]$. Among various $\mathrm{C} / \mathrm{EBP}$ isoforms, $\mathrm{C} / \mathrm{EBP} \beta$ plays a crucial role in the early stage of adipogenesis. In our current study, a high dose of ATRA $(10 \mu \mathrm{M})$ suppressed $(p<0.05)$ the expression of $C / E B P \beta$ in SC cells (Fig. 5). Unlike the SC cells, ATRA treatment did not alter $(p>0.05)$ the $C / E B P \beta$ gene expression in IM (Fig. 4). The expression of $\mathrm{C} / \mathrm{EBP} \beta$ is almost simultaneous with the induction of adipogenic stimuli. $\mathrm{C} / \mathrm{EBP} \beta$ induction leads to PPAR $\gamma$ activation, the master regulator of adipogenic differentiation, binding to their promoters [12]. In SC cells, the PPAR level tended to decrease $(p<0.1)$ in 1 and $10 \mu \mathrm{M}$ compared to Cont. In IM cells, the addition of $10 \mu \mathrm{M}$ of ATRA down-regulated $(p<0.05)$ expression of $P P A R \gamma$ compared to Cont. The difference in $\mathrm{C} / \mathrm{EBP} \beta$ expression may be one of the distinguishing characteristics of IM adipocytes. The expression of C/EBP $\beta$ in preadipocytes is initially low but dramatically increases during the early stage of terminal differentiation [13]. PPAR, a member of the nuclear hormone receptor superfamily, play a significant role in various types of cell metabolism. Three different PPAR isoforms, PPAR $\gamma$, PPARa, and PPARd have been identified. Each of these isoforms is involved in diverse physiological phenomena [14]. PPAR $\gamma$ plays an essential role during adipogenic differentiation and simultaneously controls lipid metabolism-related gene expression. In lipid and glucose metabolism, synthetic PPAR $\gamma$ ligands, including troglitazone, rosiglitazone, and pioglitazone, stimulate glucose uptake and improve insulin sensitivity in adipocytes, hepatocytes, and skeletal muscle cells [11,15]. Adipogenesis is stimulated upon the activation of PPAR $\gamma$ via 
A

SC
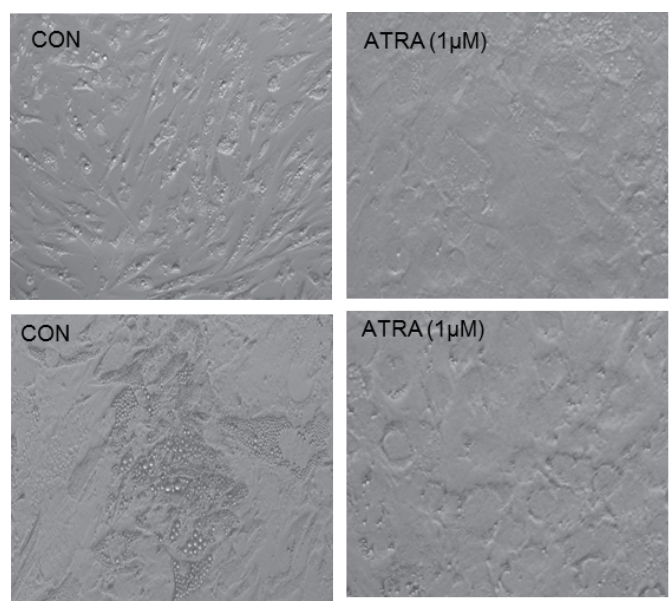

B

SC
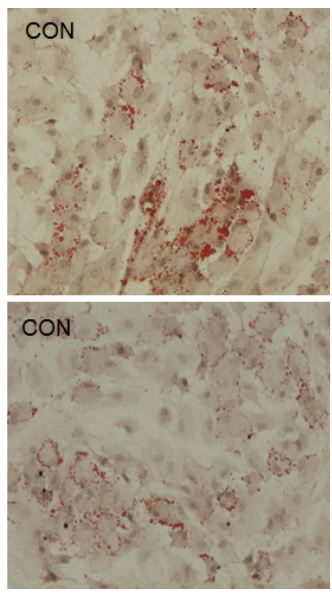
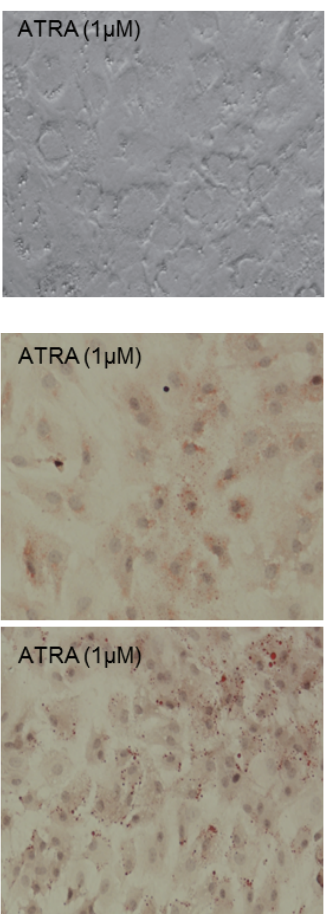
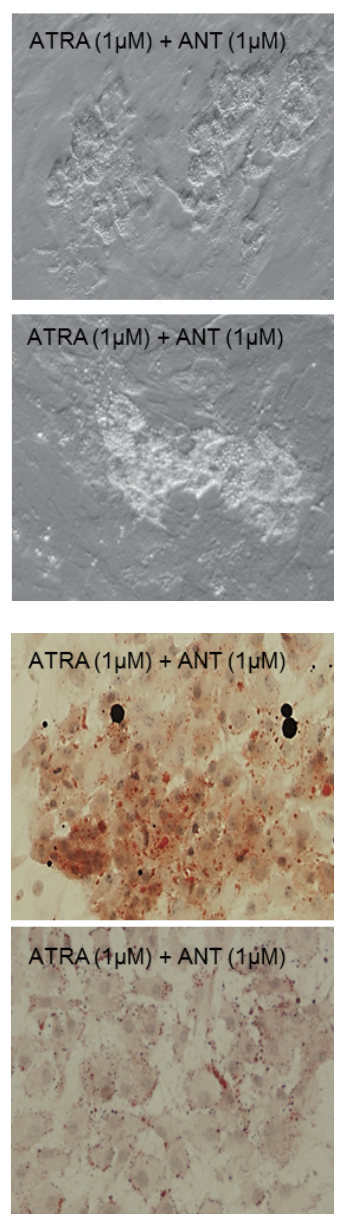

Fig. 2. Oil red $O(O R O)$ staining of retinoic acid $(1 \mu \mathrm{M})$ and retinoic acid receptor (RAR) antagonist $(1 \mu \mathrm{M})$ in bovine intramuscular (IM) and subcutaneous (SC) adipocytes at $96 \mathrm{~h}$ post-treatment. (A) Both IM and $\mathrm{SC}$ cells were imaged after $96 \mathrm{~h}$ of incubation in the differentiation media (5\% fetal bovine serum [FBS], $10 \mu \mathrm{g} /$ $\mathrm{mL}$ insulin, $10 \mu \mathrm{g} / \mathrm{mL}$ hydrocortisone, $5 \mu \mathrm{M}$ ciglitizone, and $1 \times$ Antibiotic-Antimycotic) with all-trans retinoic acid (ATRA; $1 \mu \mathrm{M}$ ) and RAR antagonist (ANT; $1 \mu \mathrm{M}$ ). Cells were imaged at a magnification of 200X with a Nikon Eclipse Ti-U microscope. A large number of lipid droplets were detected in CON and RA+ANT treatment both in SC and IM adipocytes. (B) ORO and hematoxylin were used to stain bovine SC and IM adipocytes. After $96 \mathrm{~h}$ of incubation in differentiation media, cells were fixed with $10 \%$ formalin. Lipid droplets were stained with $0.5 \%$ ORO. Nuclei were visualized with haematoxylin. Cells were imaged at a magnification of 200X with a Nikon Eclipse Ti-U microscope. Bovine SC adipocytes accumulated relatively large lipid droplets, as a result of dropletconsolidation, compared to IM adipocytes at $96 \mathrm{~h}$ of differentiation. All-trans retinoic acid treated SC and IM adipose cells showed less lipid droplets compared to CON and RA+20X.

ligands, and the mRNA level of PPAR $\gamma$ increases during bovine SC preadipocyte differentiation $[16,17]$. The inhibitory action of ATRA on adipogenic differentiation seems to be closely related to PPAR $\gamma$. To regulate the terminal differentiation of adipose cells, PPAR $\gamma$ must heterodimerize with another nuclear hormone receptor, RXR [18]. Only ATRA activates RAR moiety by binding to the ATRA response element, but 9-cis-retinoic acid can bind RXR and RAR [3]. Once ATRA binds to RAR with a high affinity and mediates the RAR/RXR heterodimer, PPAR $\gamma$ is unable to form the PPAR/RXR heterodimer. Several researchers have verified this series of PPAR $\gamma-$ involved adipogenesis blocking processes in recent decades $[3,7,8]$. To demonstrate the role of ATRA as an antagonist of RXR-PPAR $\gamma$ heterodimer formation, we tested a RAR antagonist. The results showed that the RAR antagonist activated $(p<0.05) P P A R \gamma$ genes with ATRA presence while $C / E B P \beta$. RAR antagonist seemed to accelerate the adipogenic differentiation when the high 
A
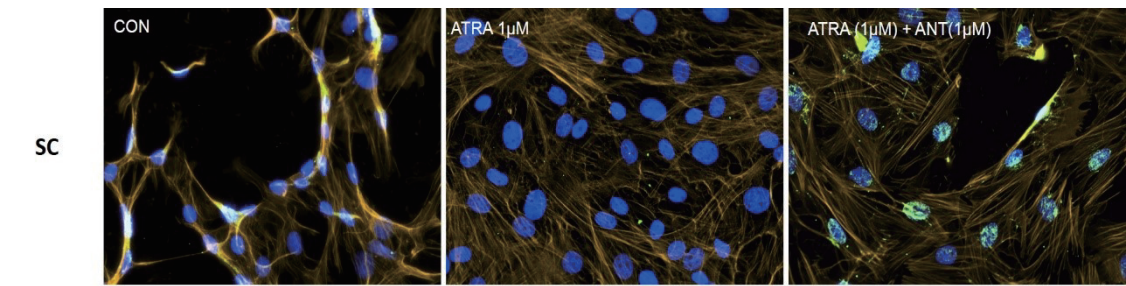

IM
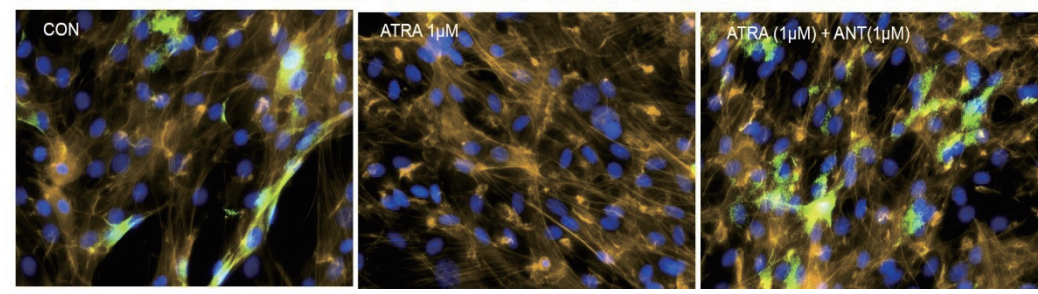

B

SC
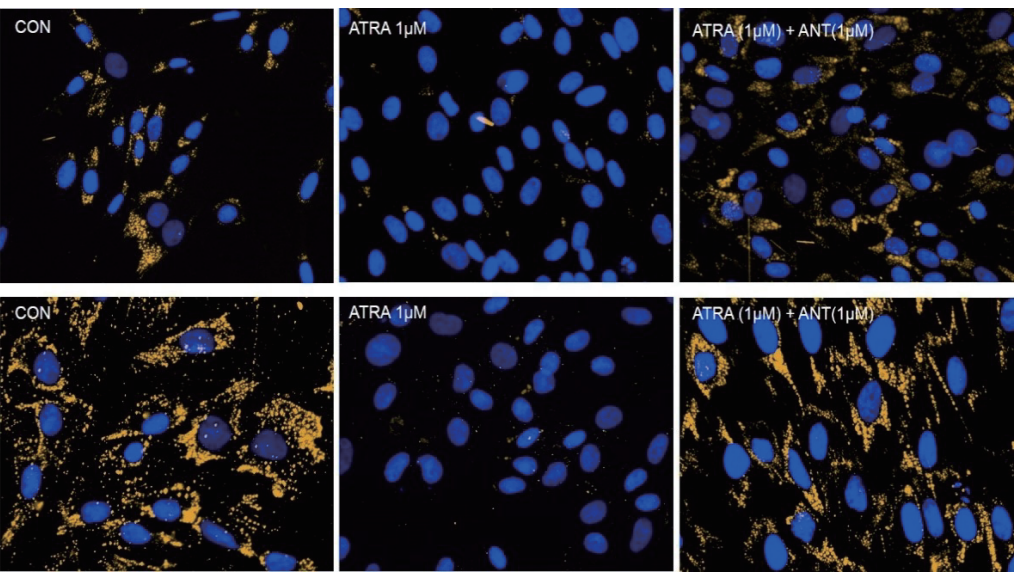

Fig. 3. Staining of peroxisome proliferator-activated receptor (PPAR)y expression and neutral lipid accumulation in bovine subcutaneous (SC) and intramuscular (IM) adipocytes. (A) Bovine IM and SC adipocytes were incubated in the differentiation media ( $\%$ fetal bovine serum [FBS], $10 \mu \mathrm{g} / \mathrm{mL}$ insulin, 10 $\mathrm{gg} /$ $\mathrm{mL}$ hydrocortisone, $5 \mu \mathrm{M}$ ciglitizone, and $1 \times$ Antibiotic-Antimycotic) with all-trans retinoic acid (ATRA; $1 \mu \mathrm{M})$ and retinoic acid receptor (RAR) antagonist (ANT; $1 \mu \mathrm{M})$. Nuclei were stained with 4',6'-diamidino-2-phenylindole (DAPI, blue). PPARy was stained with a rabbit polyclonal anti-PPAR gamma (green). F-actin was visualized with Bodipy ${ }^{\circledR} 558 / 568$ phalloidin (yellow). Slides were imaged at a magnification of 200X using an inverted fluorescence microscope. For both CON and ATRA+ANT, large amounts of PPARY accumulation within nuclei were detected in IM and SC adipose cells. (B) Nuclei were stained with DAPI (blue). Neutral lipid droplets were stained with Bodipy $\AA^{2} 493 / 503$ (Yellow). Large numbers of neutral lipid droplets were detected in CON and the ATRA+ANT treated group, both in SC and IM 20X.

dose was applied. At the point that cells were harvested, the expression of PPAR $\gamma$ was mediated by increased $C / E B P \beta$ and $C / E B P \beta$ is started to be downregulated in $10 \mu \mathrm{M}$ of RAR antagonist treated cells. The expression of $C / E B P \beta$ is rapidly increased in the early stage of differentiation, and the peak of expression of $C / E B P \beta$ preceded the accumulation of $P P A R \gamma$ mRNA and then diminished subsequently [11]. This is also confirmed by morphological analysis. RAR antagonist treatment group showed lipid droplet accumulation (Figs. 2 and 3). These sequential events transcriptionally activate genes associated with the adipogenic phenotype $[19,20]$.

\section{All-trans retinoic acid may affect subcutaneous and intramuscular in a different manner}

In the previous swine study, PPAR $\gamma$ expression was lower in IM adipocytes than SC or peripheral 
C/EBPB

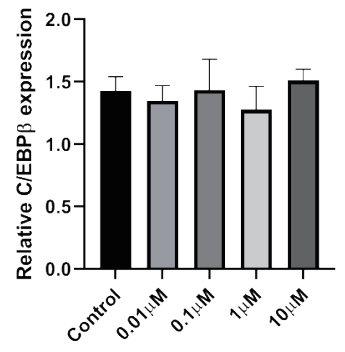

RA

LPL

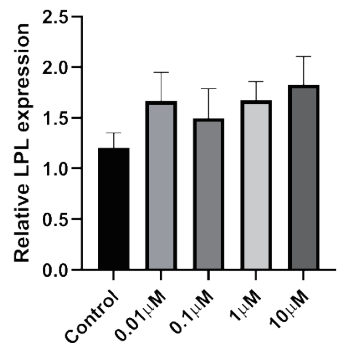

RA

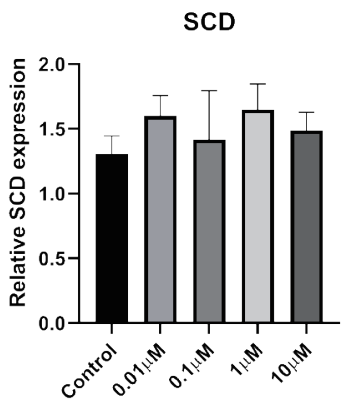

RA
GLUT4

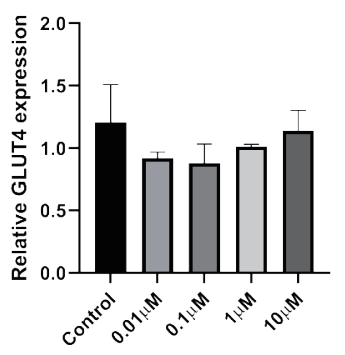

RA

PPARY

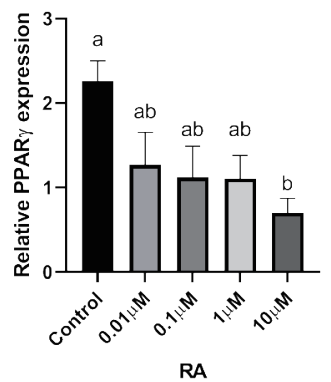

SMAD3

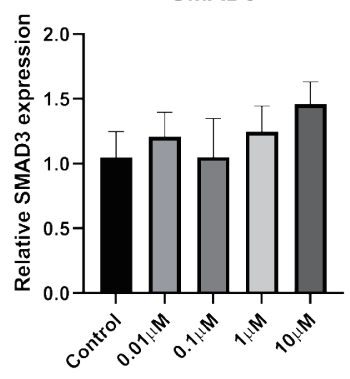

RA

Fig. 4. Expression of adipogenesis-related genes relative to RPS9 in bovine intramuscular (IM) adipose cells. Effect of 0 (control), $0.01,0.1,1$, and $10 \mu \mathrm{M}$ of all-trans retinoic acid (ATRA) on mRNA gene expressions of bovine IM adipocytes. CCAAT-enhancer-binding proteins beta (CEBP $\beta$ ), glucose transporter 4 (GLUT4), lipoprotein lipase (LPL), peroxisome proliferator activated receptor gamma (PPARY), stearoyl CoA desaturase $(S C D), S M A D$ family member 3 (SMAD3) were measured relative to the quantity of ribosomal protein S9 (RPS9) as the endogenous control by using the $2^{-\Delta \Delta \mathrm{Ct}}$ method. Superscripts $(\mathrm{a}-\mathrm{c}$ ) denote differences between treatments.

adipocytes and other genes associated with lipogenesis, including fatty acid synthase and malic enzyme [21]. It seems evident that IM and SC possess noticeable characteristics in a lipid metabolic and growth manner. First, IM and SC appear to utilize different types of substrates for lipogenesis. Smith and Crouse [22] suggested that carbon sources for the fatty acid biosynthesis differed across locations in the body; IM adipocytes preferentially used glucose, while SC adipocytes utilized acetate as a fuel source. In addition to this, IM adipose tissue used palmitic acid for triglyceride synthesis, distinctly different from SC adipose tissue [23]. Second, IM adipocytes generally show less metabolic activities compared to adipocytes in other locations such as SC and perirenal throughout the animal's growth [4]. Understanding the physiological characteristics of adipose cells in different locations, especially IM and SC, is crucial because this fat depot is directly related to the economic value of beef in many grading systems [24]. Further studies are required to 
C/EBP $\beta$

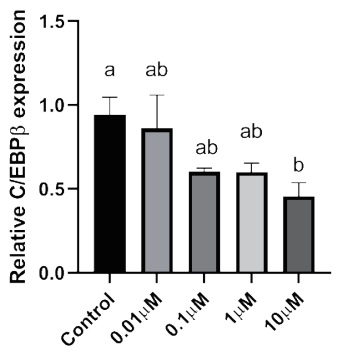

RA

LPL

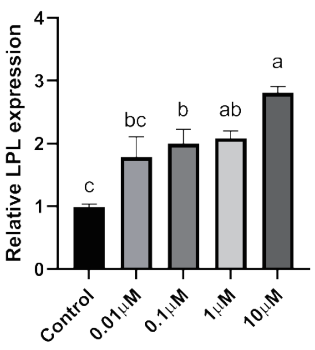

RA

SCD

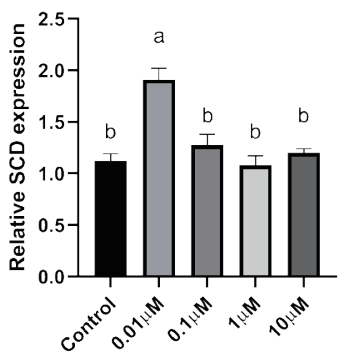

RA
GLUT4

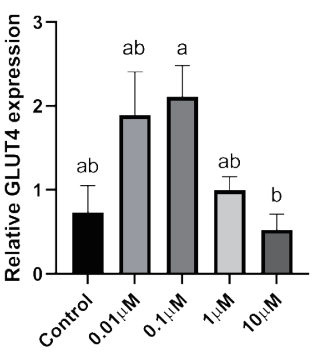

RA

PPARy

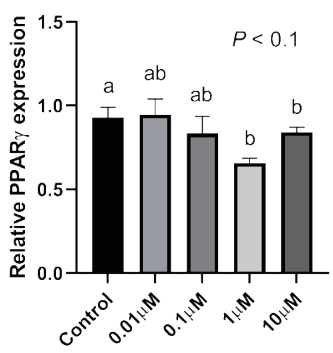

RA

SMAD3

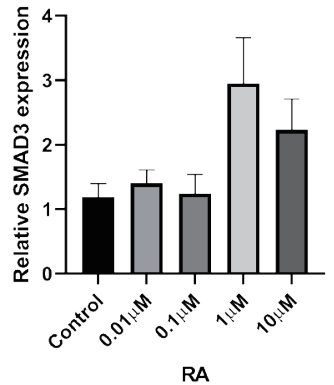

Fig. 5. Expression of adipogenesis-related genes relative to RPS9 in bovine subcutaneous (SC) adipose cells. Effect of 0 (control), $0.01,0.1,1$, and $10 \mu \mathrm{M}$ of all-trans retinoic acid (ATRA) on mRNA gene expressions of bovine SC adipocytes. CCAAT-enhancer-binding proteins beta (CEBP $\beta$ ), glucose transporter 4 (GLUT4), lipoprotein lipase (LPL), peroxisome proliferator activated receptor gamma (PPARY), stearoyl CoA desaturase (SCD), SMAD family member 3 (SMAD3) were measured relative to the quantity of ribosomal protein S9 (RPS9) as the endogenous control by using the $2^{-\Delta \Delta c t}$ method. Superscripts $(a-c)$ denote differences between treatments. ${ }^{*} p<0.1$.

develop the feeding strategy to increase IM fat without affecting the SC fat.

\section{C/EBP $\beta$ and SMAD3}

The addition of ATRA also tended to modify $(p<0.01)$ SMAD3 gene expression in both IM and $\mathrm{SC}$ adipocytes. The role of SMAD3 in the suppression of adipogenic differentiation by ATRA seems critical. It regulates adipogenesis by altering the expression of C/EBP $\beta$. Marchildon, StLouis [25] indicated that ATRA does not directly regulate C/EBP $\beta$ but indirectly stimulates the expression of the Smad3. They also identified that in the absence of Smad3, ATRA was not able to inhibit adipocyte differentiation or elicit a decrease in C/EBP. A disturbance in C/EBP $\beta$ binding to DNA response elements in promoters can occur due to the ability of Smad3 to bind to this bzip transcription factor [26]. Hence, Smad3 could be another substance involved in the inhibition of 
adipogenesis via ATRA. The ATRA treatment-induced Smad3 protein expression in 3T3-L1 cells regardless of the co-treatment with the adipogenic mixture used to induce $\mathrm{C} / \mathrm{EBP} \beta$ expression and differentiation [8].

In previous studies, retinoic acid treatments increased plasma triglycerides in human and rodent models $[27,28]$. Previous studies demonstrated that retinoic acid did not directly change LPL mRNA gene expression in 3T3-F442A [29] and primary adipose cells isolated from epididymal fat of rats [27]. ATRA may alter LPL activity in adipose tissue; however, it may be due to the secondary effect of retinoic acid but the direct regulation of the LPL gene [27]. In agreement with the previous study, our data from SC cells also indicated that the addition of ATRA did not alter LPL gene expression. However, the LPL mRNA gene expression was increased in $10 \mu \mathrm{M}$ of LPL compared to $0,0.01$, and $0.1 \mu \mathrm{M}$ of ATRA treatment (Fig. 5). Blaner and coworkers [30] reported that retinyl esters are can be substrates for LPL and suggested that LPL involve in delivering retinol to adipocytes. However, data related direct effects of ATRA on LPL gene expression on IM cells is lacking. Additional studies are required.

\section{Stearoyl-CoA Desaturase (SCD)}

The ATRA treatment did not alter $(p>0.05)$ the expression of SCD in IM cells, but $0.01 \mu \mathrm{M}$ of ATRA increased $(p<0.05) S C D$ in SC cells. The expression of the $S C D$ gene is considered a later marker in adipocyte differentiation [26]. Enzyme activity and SCD gene expression in bovine adipose tissues were reported as an indicator of fat softness and were an essential aspect of meat quality [31,32]. Kruk et al. [33] reported that dietary vitamin A restriction elevated SCD activity and enhanced marbling scores simultaneously in beef cattle. These data provide additional evidence that SCD activity is highly correlated with marbling scores. The level of SCD gene expression and SCD enzyme activity is closely associated with adipocyte differentiation in bovine IM adipose tissue [34]. In the current study, treatment of ATRA on IM did not alter the expression of SCD. Because SCD is considered a late-expression gene among adipogenic markers, $96 \mathrm{~h}$ of incubation in differentiation media may not be long enough to detect changes in SCD gene expression in IM. Contrary to this, ATRA increased SCD expression in SC adipocytes. A low concentration (0.01 $\mu \mathrm{M}$ ), possibly lower than average blood retinoic acid concentration, may increase SCD expression in $\mathrm{SC}$ adipocytes.

\section{Glucose transporter 4 (GLUT4)}

The transporter associated with glucose uptake in adipose tissue, GLUT4, gene expression was not affected by ATRA treatment in IM adipocytes. However, $0.1 \mu \mathrm{M}$ of ATRA upregulated $(p<0.05)$ the expression of GLUT4 in SC cells. A similar tendency was observed in the studies with the muscle cell. The expression of GLUT4 mRNA level was upregulated when RA was treated [35,36]. Glucose transporter 4 (GLUT4) is the major glucose translocator from the plasma membrane to intracellular storage that mainly expresses insulin-targeted tissues such as adipose and muscle tissue. There was no significant difference $(p>0.05)$ in gene expression of GLUT4 in IM adipocytes (Fig. 6). The expression GLUT4 was the greatest $(p<0.05)$ in the SC cells when $0.1 \mu \mathrm{M}$ of ATRA was added (Fig. 5). Direct effects of ATRA on GLUT4 activity in adipose cells seemed not clear. There are a few suggested indirect pathways that ATRA or other vitamin A isoforms have an impact on glucose transportation in adipose cells. Janke et al. [37] reported that retinol-binding protein 4 (RBP4), the transporter of retinol, has a positive correlation with GLUT4 in human adipose cells. Another suggested glucose uptake regulation of ATRA was via RAR signaling in the pancreas and mediated the insulin secretion [38]. 
C/EBP $\beta$

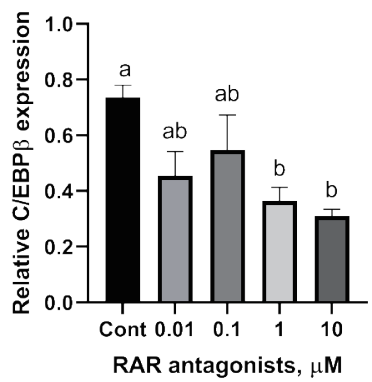

PPARY

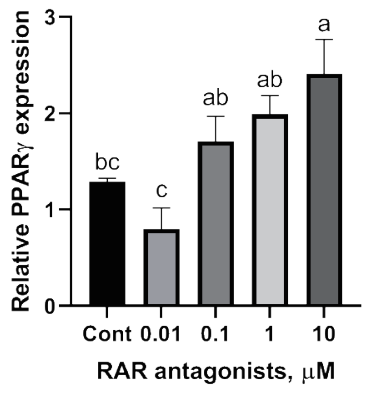

GPR43

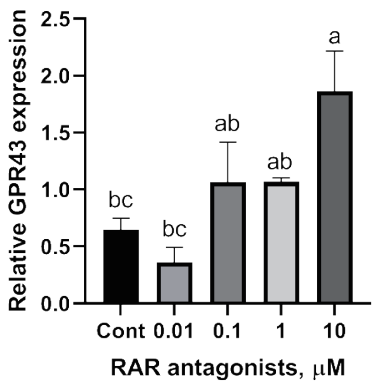

GLUT4

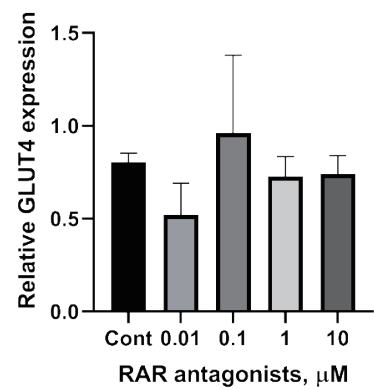

SCD

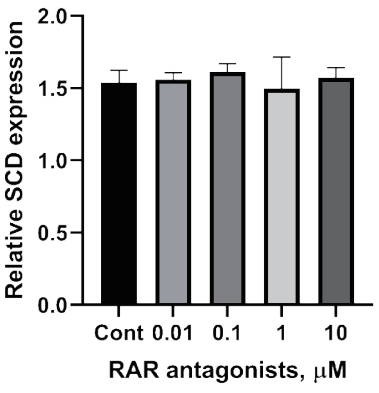

SMAD3

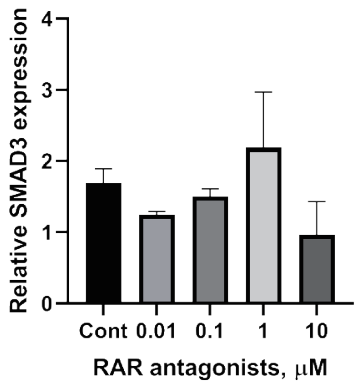

Fig. 6. Effects of retinoic acid receptor (RAR)-antagonist on adipogenesis-related gene expressions in bovine intramuscular (IM) adipose cells. Effect of 0 (control), 0.01, 0.1, 1, and $10 \mu \mathrm{M}$ of RAR antagonist on mRNA gene expressions of bovine IM adipocytes. CCAAT-enhancer-binding proteins beta (CEBP $\beta$ ), glucose transporter 4 (GLUT4), peroxisome proliferator activated receptor gamma (PPARY), stearoyl CoA desaturase (SCD), G protein-coupled receptor 43 (GPR43), SMAD family member 3 (SMAD3) were measured relative to the quantity of ribosomal protein S9 (RPS9) as the endogenous control by using the $2^{-\Delta A C t}$ method. Superscripts $(\mathrm{a}-\mathrm{c})$ denote differences between treatments.

\section{CONCLUSION}

Vitamin A deficient diet has long been used to improve IM fat contents in beef cattle in some countries. Our current study demonstrated that adipogenic differentiation could be blocked by downregulation of the genes such as C/EBP $\beta$ (SC cells) and PPAR $\gamma$ (IM- tendency, SC) when high doses of ATRA were added.

In some feeding systems, vitamin $A$ is restricted during the fattening stage. The standard fattening period for beef cattle lasts more than one-third of the lifespan; therefore, vitamin A consumption may be restricted for an extended period. Offering a minimum amount of provitamin or carotene is required to prevent health issues caused by vitamin A deficiency. 


\section{REFERENCES}

1. National Academies of Sciences, Engineering, and Medicine. Nutrient requirements of beef cattle. 8th rev. ed. Washington, DC: The National Academies Press; 2016.

2. Smith SB, Lunt DK. Marbling: management of cattle to maximize the deposition of intramuscular adipose tissue. Paper presented at: Plains Nutrition Council Spring Conference; 2007; San Antonio, Texas.

3. Villarroya F, Giralt M, Iglesias R. Retinoids and adipose tissues: metabolism, cell differentiation and gene expression. Int J Obes. 1999;23:1-6. https://doi.org/10.1038/sj.ijo.0800799

4. Hausman GJ, Poulos SP. Adipose tissue development in extramuscular and intramuscular depots in meat animals. In: Du M, McCormick RJ, editors. Applied muscle biology and meat science. Boca Raton, FL: CRC Press; 2009. p. 67-80.

5. McDowell LR. Vitamins in animal and human nutrition. Ames, IA: Iowa State University Press; 2008.

6. Suryawan $\mathrm{A}, \mathrm{Hu} \mathrm{CY}$. Effect of retinoic acid on differentiation of cultured pig preadipocytes. J Anim Sci. 1997;75:112-7. https://doi.org/10.2527/1997.751112x

7. Ohyama M, Matsuda K, Torii S, Matsui T, Yano H, Kawada T, et al. The interaction between vitamin A and thiazolidinedione on bovine adipocyte differentiation in primary culture.J Anim Sci. 1998;76:61-5. https://doi.org/10.2527/1998.76161x

8. Schwarz EJ, Reginato MJ, Shao D, Krakow SL, Lazar MA. Retinoic acid blocks adipogenesis by inhibiting C/EBPbeta-mediated transcription. Mol Cell Biol. 1997;17:1552-61. https://doi. org/10.1128/MCB.17.3.1552

9. Mercader J, Ribot J, Murano I, Felipe F, Cinti S, Bonet ML, et al. Remodeling of white adipose tissue after retinoic acid administration in mice. Endocrinology. 2006;147:5325-32. https://doi. org/10.1210/en.2006-0760

10. Moody WG, Cassens RG. A quantitative and morphological study of bovine longissimus fat cells.J Food Sci. 1968;33:47-52.https://doi.org/10.1111/j.1365-2621.1968.tb00882.x

11. Janani C, Ranjitha Kumari BD. PPAR gamma gene - a review. Diabetes Metab Syndr Clin Res Rev. 2015;9:46-50. https://doi.org/10.1016/j.dsx.2014.09.015

12. Tang QQ Lane MD. Activation and centromeric localization of CCAAT/enhancer-binding proteins during the mitotic clonal expansion of adipocyte differentiation. Genes Dev. 1999;13:2231-41. https://doi.org/10.1101/gad.13.17.2231

13. Symonds ME. Adipose tissue biology. New York, NY: Springer; 2012.

14. Tan MH. Current treatment of insulin resistance in type 2 diabetes mellitus. Int J Clin Pract Suppl. 2000;Oct:54-62.

15. van Raalte DH, Li M, Pritchard PH, Wasan KM. Peroxisome proliferator-activated receptor (PPAR)- $\alpha$ : a pharmacological target with a promising future. Pharm Res. 2004;21:1531-8. https://doi.org/10.1023/B:PHAM.0000041444.06122.8d

16. Spiegelman BM. PPAR-gamma: adipogenic regulator and thiazolidinedione receptor. Diabetes. 1998;47:507-14. https://doi.org/10.2337/diabetes.47.4.507

17. García-Rojas P, Antaramian A, González-Dávalos L, Villarroya F, Shimada A, Varela-Echavarría $\mathrm{A}$, et al. Induction of peroxisomal proliferator-activated receptor $\gamma$ and peroxisomal proliferator-activated receptor $\gamma$ coactivator 1 by unsaturated fatty acids, retinoic acid, and carotenoids in preadipocytes obtained from bovine white adipose tissue. J Anim Sci. 2010;88:18018. https://doi.org/10.2527/jas.2009-2579

18. Marill J, Idres N, Capron CC, Nguyen E, Chabot GG. Retinoic acid metabolism and mechanism of action: a review. Curr Drug Metab. 2003;4:1-10. https://doi.org/10.2174/1389200033336900 
19. Tang QQ, Otto TC, Lane MD. CCAAT/enhancer-binding protein $\beta$ is required for mitotic clonal expansion during adipogenesis. Proc Natl Acad Sci USA. 2003;100:850-5. https://doi. org/10.1073/pnas.0337434100

20. Yeh WC, Cao Z, Classon M, McKnight SL. Cascade regulation of terminal adipocyte differentiation by three members of the C/EBP family of leucine zipper proteins. Genes Dev. 1995;9:168-81. https://doi.org/10.1101/gad.9.2.168

21. Zhao S, Wang J, Song X, Zhang X, Ge C, Gao S. Impact of dietary protein on lipid metabolism-related gene expression in porcine adipose tissue. Nutr Metab. 2010;7:6. https://doi. org/10.1186/1743-7075-7-6

22. Smith SB, Crouse JD. Relative contributions of acetate, lactate and glucose to lipogenesis in bovine intramuscular and subcutaneous adipose tissue. J Nutr. 1984;114:792-800. https://doi. org/10.1093/jn/114.4.792

23. Lin KC, Cross HR, Smith SB. Esterification of fatty acids by bovine intramuscular and subcutaneous adipose tissues. Lipids. 1992;27:111-6. https://doi.org/10.1007/BF02535809

24. Smith GC, Tatum JD, Belk KE. International perspective: characterisation of United States Department of Agriculture and Meat Standards Australia systems for assessing beef quality. Aust J Exp Agric. 2008;48:1465-80. https://doi.org/10.1071/EA08198

25. Marchildon F, St-Louis C, Akter R, Roodman V, Wiper-Bergeron NL. Transcription factor $\mathrm{Smad} 3$ is required for the inhibition of adipogenesis by retinoic acid. J Biol Chem. 2010;285:13274-84. https://doi.org/10.1074/jbc.M109.054536

26. Lamarche É, Lala-Tabbert N, Gunanayagam A, St-Louis C, Wiper-Bergeron N. Retinoic acid promotes myogenesis in myoblasts by antagonizing transforming growth factor-beta signaling via C/EBP $\beta$. Skelet Muscle. 2015;5:8. https://doi.org/10.1186/s13395-015-0032-z

27. Oliver JD, Rogers MP. Effects of retinoic acid on lipoprotein lipase activity and mRNA level in vitro and in vivo. Biochem Pharmacol. 1993;45:579-83. https://doi.org/10.1016/00062952(93)90130-O

28. Lyons F, Laker MF, Marsden JR, Manuel R, Shuster S. Effect of oral 13-cis-retinoic acid on serum lipids. Br J Dermatol. 1982;107:591-5. https://doi.org/10.1111/j.1365-2133.1982. tb00411.x

29. Antras J, Lasnier F, Pairault J. Adipsin gene expression in 3T3-F442A adipocytes is posttranscriptionally down-regulated by retinoic acid. J Biol Chem. 1991;266:1157-61. https://doi. org/10.1016/S0021-9258(17)35296-1

30. Blaner WS, Obunike JC, Kurlandsky SB, Al-Haideri M, Piantedosi R, Deckelbaum RJ, et al. Lipoprotein lipase hydrolysis of retinyl ester: possible implications for retinoid uptake by cells. J Biol Chem. 1994;269:16559-65. https://doi.org/10.1016/S0021-9258(19)89425-5

31. Moseti D, Regassa A, Kim WK. Molecular regulation of adipogenesis and potential anti-adipogenic bioactive molecules. Int J Mol Sci. 2016;17:124. https://doi.org/10.3390/ijms17010124

32. Smith SB, Lin KC, Wilson JJ, Lunt DK, Cross HR. Starvation depresses acylglycerol biosynthesis in bovine subcutaneous but not intramuscular adipose tissue homogenates. Comp Biochem Physiol B Biochem Mol Biol. 1998;120:165-74. https://doi.org/10.1016/S03050491(98)10005-6

33. Kruk ZA, Bottema CDK, Davis JJ, Siebert BD, Harper GS, Di J, et al. Effects of vitamin A on growth performance and carcass quality in steers. Livest Sci. 2008;119:12-21. https://doi. org/10.1016/j.livsci.2008.02.008

34. Smith SB, Kawachi H, Choi CB, Choi CW, Wu G, Sawyer JE. Cellular regulation of bovine intramuscular adipose tissue development and composition. J Anim Sci. 2009;87:E72-82. https://doi.org/10.2527/jas.2008-1340 
35. Sleeman MW, Zhou H, Rogers S, Ng KW, Best JD. Retinoic acid stimulates glucose transporter expression in L6 muscle cells. Mol Cell Endocrinol. 1995;108:161-7. https://doi. org/10.1016/0303-7207(95)03473-K

36. Montessuit C, Papageorgiou I, Campos L, Lerch R. Retinoic acids increase expression of GLUT4 in dedifferentiated and hypertrophied cardiac myocytes. Basic Res Cardiol. 2006;101:27-35. https://doi.org/10.1007/s00395-005-0567-y

37. Janke J, Engeli S, Boschmann M, Adams F, Böhnke J, Luft FC, et al. Retinol-binding protein 4 in human obesity. Diabetes. 2006;55:2805-10. https://doi.org/10.2337/db06-0616

38. Brun PJ, Grijalva A, Rausch R, Watson E, Yuen JJ, Das BC, et al. Retinoic acid receptor signaling is required to maintain glucose-stimulated insulin secretion and $\beta$-cell mass. FASEB J. 2015;29:671-83. https://doi.org/10.1096/fj.14-256743 